\title{
Quantifying Inter-field Movements of the Western Corn Rootworm (Diabrotica virgifera virgifera LeConte) - A Central European Field Study
}

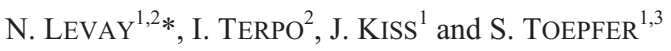 \\ ${ }^{1}$ Plant Protection Institute, Szent István University, Gödöllő, Hungary \\ ${ }^{2}$ Agro-mester Kft., Szekszárd, Hungary \\ ${ }^{3} \mathrm{CABI}$, Delémont, Switzerland \\ (Received 16 January 2014; Accepted 11 April 2014; \\ Communicated by J. Johnson)
}

\begin{abstract}
Dispersal plays a key role in the adaptation of species. It has been suggested that even in a stable and predictable environment, it is essential for any given population to "send" a certain portion of its offspring to disperse (referred as evolutionary stable dispersal rate). Although the literature on the flight behaviour of one of the major maize pests, the western corn rootworm, is rich, relatively little is known about its inter-field movements under field conditions. In the present study, inter-field movement of adult beetles was observed in Central-Europe under quasi-isolated conditions of infested continuous and un-infested first year maize fields, and related to candidate predictor variables. Percent of immigrants (net percent of adults within a given population leaving their natal maize field and arriving in first-year maize) varied greatly across years and locations $(0.4-93.3 \%$, mean $=38.7 \%)$. Results of the study provided field evidence of the assumption that western corn rootworm performs density dependent inter-field movement. Independent from pest densities, it appeared that about 1/3 of an adult beetle population always leaves its natal maize field, which likely allows the species to find new food sources and oviposition sites. The distance between maize fields and the phenological status of maize influenced inter-field movements but at a much less extent than it could have been expected from laboratory research findings.
\end{abstract}

Keywords: Zea mays, inter-field movement, dispersal, migration, continuous maize, firstyear maize, western corn rootworm, Diabrotica virgifera virgifera

\section{Introduction}

The western corn rootworm (Diabrotica virgifera virgifera LeConte, Coleoptera: Chrysomelidae) is often quoted as "a human made pest". This frequently cited expression of Krysan (1993) refers to its economic importance and its remarkable capacity of behavioural adaptation to changing agricultural environments. Adaptation, in the biological sense, is "the process of change by which an organism or species becomes better suited to

* Corresponding author; E-mail: nora.levay@hotmail.com 
its environment" (oxforddictionaries.com/definition/english/adaptation). The western corn rootworm performed such a change multiple times during its human-recorded history. Being native to subtropical America, it has spread northward to temperate climates whilst becoming a specialist for cultivated maize. This process of adaptation to maize is assumed to have taken place about a thousand year ago (Smith 1966; Branson and Krysan 1981). In the mid- $20^{\text {th }}$ century, parallel with the intensification of maize cultivation, western corn rootworm performed further spatial expansion from Nebraska, Colorado and Kansas towards the East Coast of the USA (Chiang 1973). First European report of this pest dates back to 1992 (Baca 1994), however, western corn rootworm is assumed to have arrived 8-13 years earlier (Szalai et al. 2011). Genetic variability studies indicated that multiple independent introduction events occurred in Europe (Miller et al. 2005).

The western corn rootworm is a univoltine insect pest, laying eggs from mid-summer until the first frosts in autumn, under temperate climate. After overwintering as eggs, larva hatch during the spring of the following year. The larva can successfully end its development almost exclusively on the roots of maize (Chiang 1973). From the view point of pest population survival, the most important question is whether or not there will be maize grown in the following growing season in that field where females laid their eggs in the previous year. Therefore, crop rotation is the most effective non-chemical control tool for this pest. Despite being an effective control option, farmers in Europe are often reluctant to accept rotation, since maize is one of the most profitable field crops in many regions (Fall and Wesseler 2008). Moreover, annual rotation of all maize fields seems unnecessary both from theoretical viewpoint (Szalai et al. 2014) and based on field observations (Kiss 2005; Ripka 2008). In their computer simulation, Szalai et al. (2014) showed that keeping $20-30 \%$ continuous maize in the area-wide rotation scheme can sustain the pest population level under economic threshold. The essence of this phenomenon lays in the inter-field movements of western corn rootworm, i.e. continuous maize fields act as reservoirs of emigrating adults resulting in a dilution of population at the landscape level.

Dispersal strategies of species play a key role in the adaptation to the changing environment. It is an energy-demanding process and a behaviour that is subject to increased mortality. If conditions are too feeble to be worthwhile to stay in a particular habitat patch, clearly the risk of dispersal must be taken. However, dispersal is much more than merely avoiding unfavourable biotic or abiotic conditions. It has been mathematically proven that even in stable, uniform and predictable environment it is essential for any given population that a certain percentage of its offspring take the risk of dispersal (referred as evolutionary stable dispersal rate) (Hamilton and May 1977; Comins et al. 1980). Analyzing the evolution of dispersal rates in spatially and temporally varying environments, McPeek and Holt (1992) concluded that some level of dispersal evolves under "almost all regimes of habitat variability". The evolution of dispersal strategies has been in the forefront of behavioural ecology studies for a long time. According to our present knowledge both external (habitat carrying capacity, patch quality, local catastrophes) and internal (chaotic population dynamics, demographic stochasticity) factors act as driving forces in the selection for different dispersal strategies (Comins et al. 1980; Cohen and Levine 1991; McPeek and Holt 1992; Olivieri et al. 1995; Holt and McPeek 1996; Cadet et al. 2003). In reflec- 
tion to this complex issue, it is particularly challenging to gain deeper insight into the different selection pressures dynamically forming dispersal rates in the spatiotemporally varying agricultural landscapes. As for western corn rootworm, the survival of the subsequent generation depends on the fact whether there is maize grown in the following growing season in that location where females laid their eggs previously. Intuitively one would expect a certain rate of dispersal in order to maximize the likelihood of the population's survival. Experimental data are available on the percent of beetles performing sustained flight under laboratory conditions (Coats et al. 1986; Naranjo 1990). Field studies identified some external environmental factors as driving forces beyond inter-field movements of adult beetles (Naranjo 1991, 1994; Darnell et al. 2000; Campbell and Meinke 2006). Nevertheless, the question naturally arises: is there any evidence for the existence of a dispersal that is independent from stress factors? How do different (environmental and non-environmental, external vs. internal) factors act together resulting in such inter-field movements that we might call "a dispersal strategy" of the western corn rootworm? The aim of this study was to investigate these questions. Field experiments were conducted in order to quantify the rate of immigration from infested continuous into first-year maize fields in a quasi-isolated field pair setup. Percent of immigrants was then related to external and internal factors as candidate predictor variables of inter-field movement.

\section{Materials and Methods}

\section{Experimental sites}

The field setup was the key concept in this study since the setup itself made it possible to quantify the magnitude of inter-field movements of adult beetles. An elaborate search for suitable pairs of maize fields was conducted; one pair of fields consisted of a continuous maize field and a first-year maize field at a given distance from each other. The field pairs were "quasi-isolated", i.e. within a $3 \mathrm{~km}$ radius circle around the first year maize field, the only other maize field was the corresponding continuous maize field. Therefore, within a given field pair, the corresponding continuous maize field was supposed to be the only source of immigrant adults into the first-year maize field. In total, 20 pairs of such maize fields were found and studied in southern Hungary (Tolna and Csongrád Counties) in 2006 and 2007. Non-baited yellow sticky traps (Pherocon AM, Trece Inc., USA) were assessed to quantify adult movements. Three traps were placed in each field, the first one being placed $20 \mathrm{~m}$ from the field edge then $40 \mathrm{~m}$ distance between each trap. Traps were fixed on maize plants at ear height and were changed on weekly basis. Traps were located in that part of the fields that was closest to their corresponding field pair.

Distances were measured between the closest points of the fields within a pair. Distances within pairs varied between $0.7 \mathrm{~m}$ (the two fields were ploughed into one unit) and $1380 \mathrm{~m}$ (GPS Garmin, USA). In 38 fields of the total, maize was grown for grain fodder production and in 2 fields for seed production. In four fields there was aerial insecticide application against western corn rootworm adults in 2007. In all four cases pyrethroid (Karate Zeon, active ingredient: lambda-cyhalothrin, Syngenta) was applied. Dates were 
recorded and capture data of that week following the date of insecticide application, were ignored in the statistical analysis. Eight fields were properties of agricultural corporations, whereas 32 fields were properties of private farmers. All fields were managed according to the agronomic practices typical in the region. There was no irrigation in any of the fields. Sizes of fields varied between 0.5 and 122 hectares $(\operatorname{mean}=23.7$, s.d. $=35.6)$. Dates of trap changes and the length of sampling period varied between years and among field pairs. In 2007 maize was typically harvested earlier due to spring and summer drought in Hungary, so the sampling periods were sometimes shorter compared to 2006.

Altogether 4 weeks capture data for all 20 pairs of fields ( $n=80$ data) were considered in statistical analysis between $1^{\text {st }}$ of July and $19^{\text {th }}$ of August. The reason for using 4 weeks data was (a) that this is the period when populations have still not largely declined due to natural mortality factors, and (b) that different types of disturbances occurred in the experimental sites during the growing season (early harvest, early senescence of plants due to heavy drought). Further on, time was expressed as Julian Days. In case of seven pairs of fields, phenological stages of both first-year and corresponding continuous maize fields were recorded weekly in 2007 ( $n=28$ data). Data collectors recorded the estimated (i) percentage of pollinating maize plants within fields, (ii) percentage of maize plants with fresh silks within fields and (iii) percentage of green leaf surface within fields, at each trap change event. The arithmetic mean of these three ratios represented the phenological attractiveness of the given maize field, where value of 1 was given for a green maize field in full pollination and with all plants offering fresh silks. In contrast, value of 0 meant a completely dry, senescent maize field. In practice, none of the fields got the value of zero since data recording was terminated before reaching this stage. Relative phenological attractiveness was calculated as follows: the phenological index of first year maize field minus the phenological index of the corresponding continuous maize field. This value was positive if the first year maize field was more attractive than its corresponding continuous maize field.

\section{Data transformation and statistical analysis}

Captured adult western corn rootworms were counted and males/females separated based on antenna length and elytra colouring (Staetz et al. 1976; Kuhar and Youngman 1995). Captures were expressed as adults/trap/day, which was, in all cases, the mean of the 3 traps/field. Since in most cases the sizes of fields within pairs were different, capture data of all first year maize fields were corrected to the size of their corresponding continuous maize fields, setting the raw capture data to a 1:1 ratio of field sizes. Therefore, raw capture data (adults/trap/day) of first year maize fields were divided by a correction factor $(\mathrm{CF})$, where $\mathrm{CF}=$ size of continuous maize field/size of corresponding first year maize field.

This correction of raw capture data has been justified by the fact that the same population density (adults/trap/day) in a bigger field means greater absolute number of immigrant adults than the same density in a smaller field. The percent of immigrants (dependent variable) was derived from the size-corrected capture data as follows. The weekly total capture of the given field pair was taken as $100 \%$ of the continuous maize field's naturally 
emerged population. The 'percent of immigrants' was then expressed as the ratio of firstyear maize field's captured adults out of the total capture. Sex ratio of captured western corn rootworm adults was expressed as [male : female] whenever there were captures of both sexes. Statistical analysis was run in the R language (R Development Core Team 2008). The following statistical procedures were conducted: Pearson product-moment correlation, null hypothesis significance testing, simple and multiple regression analysis with calculation of confidence intervals, Levene's procedure, Tukey's test and Student's independent $t$-test.

\section{Results}

All of the studied first-year maize fields were successfully colonized by immigrating western corn rootworm adults. Mean percent of immigrants was 38.7\% \pm 29.4 ( $n=20$ field pairs). This number represents the percent of adults in a given population leaving its natal maize field for a new habitat patch. However, percent of immigrants varied greatly across years and study locations, ranging from $0.4 \%$ to $93.3 \%$ (Table 1 ). The mean percent of immigrants was significantly higher in 2007 than in 2006 (independent $t$-test, $p<0.05$ ).

Mean population density was $7.0 \pm 9.4$ adults/trap/day on average for the two years and 20 field pairs. The average population density did not differ between the two years (independent $t$-test, $p=0.43$ ). Densities ranged from 0.09 to 15.06 in continuous maize fields and from 0.05 to 11.4 in first-year maize fields (adults/trap/day). There was a moderate, significant positive correlation between total population density and percent of immigrants $(r=0.43, p<0.05)$ but no other variable proved to be significantly correlated with percent of immigrants, i.e. neither the time period of the growing season (Julian Days), nor the distance between fields and none of the phenological indices (Table 2).

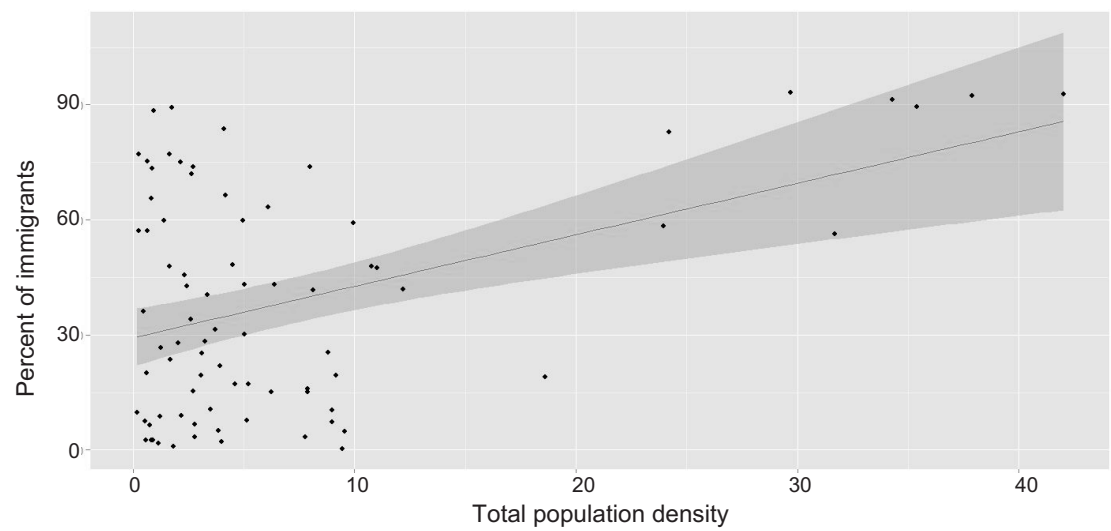

Figure 1. Percent of immigrants of adult western corn rootworm beetles in response to the total population density presented through a simple regression model on the pooled dataset, the dark shaded region represents confidence interval. $\mathrm{Y}=29.25+1.34 \mathrm{X}$ where $\mathrm{Y}$ is percent of immigrants $[\%]$ and $\mathrm{X}$ is the total population density [adults/trap/day] $\left(\mathrm{R}^{2}=0.1835, p<0.05, \mathrm{df}=78\right.$, conf $_{95}$ for the regression coefficient: $0.70-1.98$ and for the intercept: 21.81-36.69) 


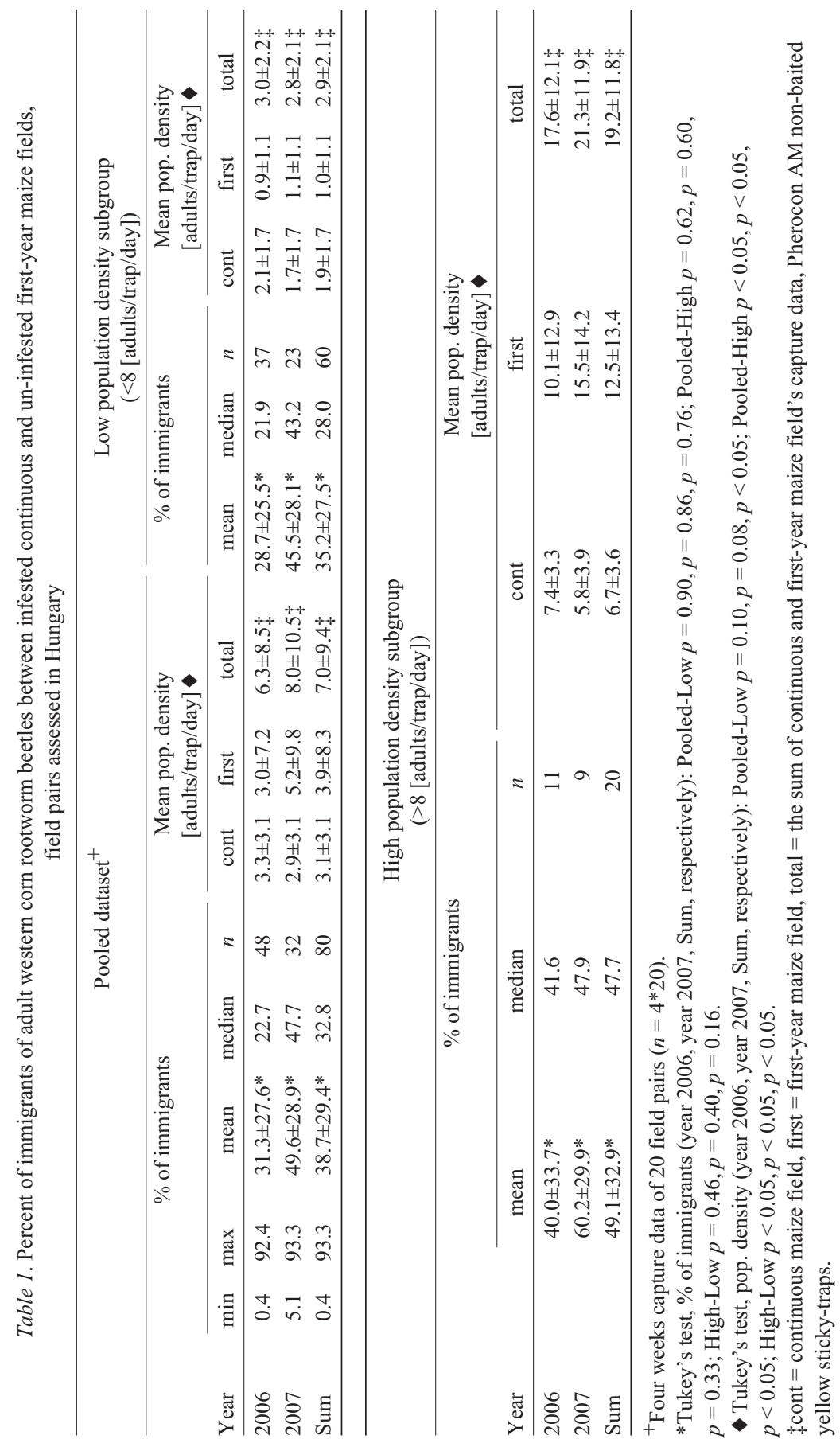


The scatter plot of percent of immigrants in response to total population density implied the existence of two different patterns: at low population densities there seemed to be no clear pattern of any relationship between percent of immigrants and total population density, whereas at high population densities a strong positive correlation seemed to be present (Fig. 1). Thus, the original dataset was divided into two groups, i.e. low density group (total population density $<8$ adults/trap/day) and high density group (total population density $>8$ adults/trap/day). Although mean percent of immigrants in the low density group was slightly lower than the pooled average, whereas it increased in the high population density group, the differences were not significant (Tukey's test) (Table 1). Correlation analysis showed that in the low population density group none of the candidate predictor variables had significant correlation with percent of immigrants. In contrast, the correlation between percent of immigrants and total population density became particularly strong in the high population density group (Table 2 ).

Table 2. Factors influencing percent of immigrants of adult western corn rootworm beetles between infested continuous and un-infested first year maize fields (Hungary, 2006-2007)

\begin{tabular}{lcc}
\hline Factors & Percent of immigrants \\
\hline Pooled dataset & Pearson's correlation $(r)$ & df \\
Total population density [adults/trap/day] & $\mathbf{+ 0 . 4 3}(\boldsymbol{p}<\mathbf{0 . 0 5})$ & 78 \\
Distance between fields & $-0.09(p=0.24)$ & 78 \\
Julian Days & $+0.09(p=0.41)$ & 78 \\
Phenological index of continuous maize fields (=C) & $-0.09(p=0.64)$ & 26 \\
Phenological index of first-year maize fields (=F) & $-0.08(p=0.69)$ & 26 \\
Relative phenological attractiveness (=F-C) & $+0.30(p=0.12)$ & 26 \\
\hline Low population density subgroup (<8 [adults/trap/day]) & Pearson's correlation $(r)$ & $\mathrm{df}$ \\
Total population density [adults/trap/day] & $-0.09(p=0.51)$ & 58 \\
Distance between fields & $+0.25(p=0.05)$ & 58 \\
Julian Days & $+0.11(p=0.40)$ & 58 \\
Phenological index of continuous maize fields (=C) & $-0.27(p=0.27)$ & 17 \\
Phenological index of first-year maize fields (=F) & $-0.02(p=0.91)$ & 17 \\
Relative phenological attractiveness (=F-C) & $+0.44(p=0.06)$ & 17 \\
\hline High population density subgroup( $>\mathbf{8}$ [adults/trap/day]) & df \\
Total population density [adults/trap/day] & Pearson's correlation $(r)$ & 18 \\
Distance between fields & $+\mathbf{0 . 8 4}(\boldsymbol{p}<\mathbf{0 . 0 5})$ & 18 \\
Julian Days & $-0.31(p=0.18)$ & 18 \\
Phenological index of continuous maize fields (=C) & $0.00(p=0.99)$ & 7 \\
Phenological index of first-year maize fields (=F) & $+0.22(p=0.56)$ & 7 \\
Relative phenological attractiveness (=F-C) & $+0.28(p=0.48)$ & 7 \\
\hline
\end{tabular}

Simple regression analysis on the pooled dataset, with the independent variable total population density (X), explained $18 \%$ of the variance in percent of immigrants (Fig. 1). Multiple linear regression model with two independent variables total population density $\left(\mathrm{X}_{1}\right)$ and distance between fields $\left(\mathrm{X}_{2}\right)$ explained $24 \%$ of the variance (pooled dataset, $\mathrm{Y}=$ $\left.23.98+1.51 \mathrm{X}_{1}+0.02 \mathrm{X}_{2}, R^{2}=24 \%, p<0.05, \mathrm{df}=77\right)$. Analysis of variances justified the better fit of the multiple regression model on the data $(F=0.02)$. Inclusion of relative 
phenological attractiveness as independent variable in the linear multiple regression model, did not result in significantly better prediction of percent of immigrants. Regression models were fitted and tested on the two subsets of data as well. In the low population density group none of the tested regression models gave significant result. In the high population density group, simple regression analysis with total population density as independent variable explained $70 \%$ of variance $\left(\mathrm{Y}=4.38+2.32 \mathrm{X}, R^{2}=0.7019, p<0.05, \mathrm{df}=\right.$ 18). However, the best fit to the data was obtained if three independent variables were included in the regression model: total population density $\left(\mathrm{X}_{1}\right)$, distance between fields $\left(\mathrm{X}_{2}\right)$ and relative phenological attractiveness $\left(\mathrm{X}_{3}\right)$. This multiple linear model explained $78 \%$ of variance despite the fact that as stand-alone variables, neither distance, nor phenological attractiveness was significant predictor of percent of immigrants $\left(\mathrm{Y}=51.21+1.14 \mathrm{X}_{1}-\right.$ $0.41 \mathrm{X}_{2}-45.37 \mathrm{X}_{3}, R^{2}=0.7756, p<0.05, \mathrm{df}=5$ ).

The difference in sex ratios of adult beetles between continuous and first-year maize fields was not significant: neither in the pooled dataset, nor when being separated by years. Sex ratio of both continuous and first-year maize fields was skewed towards males, which is a result of the capture characteristics of the traps (see discussion). Mean sex ratio was $10.28[\mathrm{males} / \mathrm{females}]($ s.d. $=14.13, n=55)$ and $7.34[\mathrm{males} / \mathrm{females}]($ s.d. $=12.30$, $n=55$ ) in continuous and first-year maize fields, respectively. Although relatively more females were captured in first-year maize (dispersing adults) than in continuous maize (non-dispersing adults), the difference was not significant (independent $t$-test, $p=0.247$, $p=0.227$ and $p=0.587$ for the pooled dataset, 2006 and 2007, respectively). Interestingly, the difference between years was significant, i.e. relatively more females were trapped in 2007 compared to 2006 in both continuous and first year maize fields (independent $t$-test, $p<0.05$ ), however, still more males were present in the traps.

\section{Discussion}

All of the first-year maize fields were successfully colonized within the 4 weeks period in July and August each year, indicating that distance between maize fields up to $1.38 \mathrm{~km}$ was not a barrier for western corn rootworm adults. Percent of immigrants varied greatly over time (between years, among field pairs), however, a "baseline movement pattern" was observed that seemed to be independent from all the studied potentially influencing factors and varied around one third of the population (depending on which regression model was taken into account). These findings are in line with Coats et al. (1986) reporting that $31 \%$ of mated western corn rootworm females performed sustained migratory flight in a flight mill experiment. Similarly, Naranjo (1990) reported that $24 \%$ of mated, $2-7$ days old females engaged in sustained flight (longer than $20 \mathrm{~min}$ ) under laboratory conditions. In our study, western corn rootworm adults exhibited two different inter-field movement patterns under field conditions. Below a population density of 8 adults/trap/day, the "baseline movement pattern" was expressed. Percent of immigrants fluctuated around one third of the population and it was impossible to build any statistical model which could predict this fluctuation. On the contrary, above the threshold, inter-field movement became density dependent. The population density factor alone could reliably predict per- 
cent of immigrants in simple regression analysis. This fact, i.e. that western corn rootworm exhibits different inter-field movement patterns under different population densities, is one of the numerous examples of density dependence in behavioural ecology (Campbell et al. 2005).

Both field observations and laboratory studies confirm that western corn rootworm has a preference for maize at habitat interfaces (Naranjo 1994; Spencer et al. 1999; Campbell and Meinke 2006), and is capable of actively orienting its flight towards maize fields (Naranjo 1994; Toepfer et al. 2006). Moreover it prefers phenologically less mature maize (Naranjo 1991, 1994), which was also found in the present study. Once an adult initiates a sustained flight, it prefers longer distances and is capable of covering $3.6 \mathrm{~km}$ on average under laboratory conditions (Coats et al. 1986). Although the influence of distance and crop phenology on inter-field movement was statistically detectable in our field study as well, the impact of these variables was far weaker than expected based on previous laboratory research findings. As a stand-alone factor, neither of them was good enough predictor of inter-field movement. Only in combination with population density, could these two variables contribute to a regression equation of strong predictive power.

Although, relatively more females were present in first year maize compared to continuous maize field, indicating and increased percentage of females being engaged in inter-field movements, this difference was statistically not significant. The relative dominance of males in the trap captures was probably due to the fact that Pherocon AM yellow sticky traps attract males stronger than females (Kuhar and Youngman 1995).

Results of this study provide field evidence of a long-standing assumption that western corn rootworm performs density dependent inter-field movement. Moreover, regression models of inter-field movement can be used in landscape level population dynamic modelling. Therefore, it can be used for simulating area-wide population dilution process over a fragmented agricultural landscape where both continuous and first-year maize fields are present in the rotation scheme.

\section{Acknowledgements}

Authors of this publication acknowledge the support of farmers who provided field experimental sites for the work. This research was supported by the Research Centre of Excellence project (17586-4/2013/TUDPOL).

\section{References}

Baca, F. 1994. New member of the harmful entomofauna of Yugoslavia Diabrotica virgifera virgifera LeConte (Coleoptera: Chrysomelidae). Zastita Bilja 45:125-131.

Branson, T.F., Krysan, J.L. 1981. Feeding and oviposition behaviour and life cycle strategies of Diabrotica: An evolutionary view with implication to pest management. Environ. Entomol. 10:826-831.

Cadet, C., Ferriere, R., Metz, J.A.J., van Baalen, M. 2003. The evolution of dispersal under demographic stochasticity. Am. Naturalist 162:427-441.

Campbell, L.A., Meinke, L.J. 2006. Seasonality and adult habitat use by four Diabrotica species at prairie-corn interfaces. Environ. Entomol. 35:922-936. 
Campbell, N.A., Reece, J.B., Urry, L.A., Molles, M., Zimmer, C., Wills, C., Minorsky, P.V., Niles, M.J., Stretton, A. 2005. Behavioral ecology. In: Campbell, N.A., Reece, J.B. (eds), Campbell Biology. Chapter 51. Benjamin Cummings. San Francisco, USA, pp. 1106-1134.

Chiang, H.C. 1973. Bionomics of the northern and western corn rootworms. Annu. Rev. Entomol. 18:47-72.

Coats, S.A., Tollefson, J.J., Mutchmor, J.A. 1986. Study of migratory flight in western corn rootworm (Coleoptera: Chrysomelidae). Environ. Entomol. 15:620-625.

Cohen, D., Levine, S.A. 1991. Dispersal in patchy environments: The effects of temporal and spatial structures. Theor. Popul. Biol. 39:63-99.

Comins, H.N., Hamilton, W.D., May, R.M. 1980. Evolutionary stable dispersal strategies. J. Theor. Biol. 82:205-230.

Darnell, S.J., Meinke, L.J., Young, L.J. (2000): Influence of corn phenology on adult western corn rootworm (Coleoptera: Chrysomelidae) distribution. Environ. Entomol. 29:587-595.

Fall, E.H., Wesseler, J.H.H. 2008. Practical compatibility and economic competitiveness of each biological control option with chemical control and with cultural control of WCR (WP 2 Task 3). <http://diabract. vitamib.com/documents/d02-16-report-on-practical-compatibility-and-economiccompetitiveness-of-eachbiological-control-option-with-chemical-controland-with-cultural-control-of-wcr-wp-2-task-3>

Hamilton, W.D., May, R.M. 1977. Dispersal in stable habitats. Nature 269:578-581.

Holt, R.D., McPeek, M.A. 1996. Chaotic population dynamics favours the evolution of dispersal. Am. Naturalist 148:709-718.

Kiss, J. 2005. WCR Risk Estimation for developing IPM in maize. GTFS/RER/017/ITA "Integrated Pest Management for Western Corn Rootworm in Central and Eastern Europe" FAO Project Report. http://www.fao.org/fileadmin/user_upload/oed/docs/GTFSRER017ITA_2008_ER.pdf

Krysan, J.L. 1993. Adaptations of Diabrotica to habitat manipulations. In: Kim, K.C., McPheron, B. (eds), Evolution of Insect Pests and Patterns of Variation. John Wiley and Sons, Inc., New York, USA, pp. 361-373.

Kuhar, T.P., Youngman, R.R. 1995. Sex ratio and sexual dimorphism in western corn rootworm (Coleoptera: Chrysomelidae) adults on yellow sticky traps in corn. Environ. Entomol. 24:1408-1413.

McPeek, M.A., Holt, R.D. 1992. The evolution of dispersal in spatially and temporally varying environments. Am. Naturalist 140:1010-1027.

Miller, N., Estoup, A., Toepfer, S., Bourguet, D., Lapchin, L., Derridj, S., Kim, K.S., Reynaud, P., Furlan, L., Guillemaud, T. 2005. Multiple transatlantic introductions of the western corn rootworm. Science (Washington) 310:992.

Naranjo, S.E. 1990. Comparative flight behaviour of Diabrotica virgifera virgifera and Diabrotica barberi in laboratory. Entomol. Exp. Appl. 55:79-90.

Naranjo, S.E. 1991. Movement of corn rootworm beetles, Diabrotica spp. (Coleoptera: Chrysomelidae), at cornfield boundaries in relation to sex, reproductive status and crop phenology. Environ. Entomol. 20:230-240.

Naranjo, S.E. 1994. Flight orientation of Diabrotica virgifera virgifera and Diabrotica barberi (Coleoptera: Chrysomelidae) at habitat interfaces. Ann. Entomol. Soc. Am. 87:383-394.

Olivieri, I., Michalakis, Y., Gouyon, P.H. 1995. Metapopulation genetics and the evolution of dispersal. Am. Naturalist 146:202-228.

R Development Core Team. 2008. R: A language and environment for statistical computing. R foundation for Statistical Computing, Vienna, Austria. ISBN 3-900051-07-0, URL: http://www.R-project.org

Ripka, G. 2008. Egy állandósult, de nem megoldhatatlan növényvédelmi gond: az amerikai kukoricabogár. [A permanent but not insolvable pest problem: the western corn rootworm.] Gyakorlati Agrofórum 19:64-66. (in Hungarian)

Smith, R.F. 1966. Distributional patterns of selected western North American insects: The distribution of diabroticites in western North America. Bull. Entomol. Soc. Am. 12:108-110.

Spencer, J.L., Isard, S.A., Levine, E. 1999. Free flight of western corn rootworm (Coleoptera: Chrysomelidae) to corn and soybean plants in a walk-in wind tunnel. J. Economic Entomol. 92:146-155.

Staetz, C.A., Ball, H.J., Carlson, S.D. 1976. Antennal morphology of Diabrotica virgifera adults (Coleoptera: Chrysomelidae). Ann. Entomol. Soc. Am. 69:695-698.

Szalai, M., Komaromi, J.P., Bazok, R., Barcic, J.I., Kiss, J., Toepfer, S. 2011. Generational growth rate estimates of Diabrotica virgifera virgifera populations (Coleoptera: Chrysmelidae). J. Pest Sci. 84:133-142. 
Szalai, M., Kiss, J., Kover, Sz., Toepfer, S. 2014. Simulating crop rotation strategies with a spatiotemporal lattice model to improve legislation for the management of the maize pest Diabrotica virgifera virgifera. Agricult. Systems 124:39-50.

Toepfer, S., Levay, N., Kiss, J. 2006. Adult movements of newly introduced alien Diabrotica virgifera virgifera (Coleoptera: Chrysomelidae) from non-host habitats. Bull. Entomol. Res. 96:327-335. 